\title{
Functionalised natural zeolite and its potential for treating drinking water containing excess amount of nitrate
}

\author{
Maurice S Onyango ${ }^{1 *}$, Mike Masukume ${ }^{1}$, Aoyi Ochieng ${ }^{2}$ and Fred Otieno ${ }^{4}$ \\ ${ }^{1}$ Department of Chemical and Metallurgical Engineering, Tshwane University of Technology, South Africa \\ ${ }^{2}$ Department of Chemical Engineering, Vaal University of Technology, South Africa \\ ${ }^{3}$ Faculty of Engineering and the Built Environment, Tshwane University of Technology, South Africa \\ ${ }^{4}$ Faculty of Engineering and the Built Environment, Durban University of Technology, PO Box 1334 Durban, South Africa
}

\begin{abstract}
An excess level of nitrate in drinking water is responsible for methemoglobinemia, or 'blue baby' disease. Consequently, management of nitrate in drinking water is universally of public health interest. In this study, clinoptilolite functionalised with cationic surfactant hexadecyltrimethyl ammonium (HDTMA) was used for the removal of nitrate from drinking water. The effects of surfactant loading, adsorbent dosage, $\mathrm{pH}$, coexisting ions, temperature and environmental water quality on the adsorption of nitrate were investigated. It was found that adsorption was optimum when the initial concentration of the functionalising surfactant was $3000 \mathrm{mg} \cdot \ell^{-1}$. An increase in adsorbent dosage raised the percentage removal of nitrate. The valency of the coexisting anion had a major effect on nitrate removal, with the presence of phosphate (a trivalent anion) leading to the lowest removal ability. Temperature and $\mathrm{pH}$ had negligible effects on adsorbent performance. Environmental water samples (natural groundwater samples from Limpopo Province, South Africa) were tested and it was found that the World Health Organisation (WHO) regulatory compliance can be achieved even when the initial concentration of nitrate exceeds $300 \mathrm{mg} \cdot \ell^{-1}$. Equilibrium data was modelled using the Freundlich and Langmuir isotherms and the data conformed well to the Freundlich isotherm, indicating the heterogeneous nature of the active sites. Kinetically, nitrate adsorption was best described by the pseudo-second rate equation.
\end{abstract}

Keywords: adsorption, zeolite, nitrate, kinetics, equilibrium

\section{Introduction}

A number of rural communities in South Africa use groundwater for drinking purposes. In some cases this water is impure due to high concentrations of nitrates (Schoeman and Steyn, 2003). Pietersen (2005) reported that groundwater in South Africa often has high nitrate values, which exceed $50 \mathrm{mg} \cdot \ell^{-1}$, the limit recommended by the world Health Organisation (WHO). Colvin et al. (2008) further noted that South Africa has some of the highest natural nitrate levels in the world $\left(>500 \mathrm{mg} \cdot \ell^{-1}\right.$ $\mathrm{NO}_{3}-\mathrm{N}$ ). Nitrates can spread in the environment either naturally or due to anthropogenic activities (Stadler et al., 2008). It is well recognised that the presence of excess nitrates in drinking water can be detrimental to a variety of living species, including man. A high concentration of nitrate in drinking water leads to production of nitrosamine, which is related to cancer and increases the risk of diseases such as methemoglobinemia in newborn infants (Mažeikienè et al., 2008; Bouwer, 1989; Samatya et al., 2006). Hence, reduction of nitrates in drinking water to permissible levels is mandatory.

A number of physico-chemical technologies, such as reverse osmosis (Bohdziewicz, 1999), ion exchange (Bae et al., 2002; Clifford and Liu, 1993) and chemical precipitation (Ayyasamy et al., 2007) are available for nitrate removal from water (Schoeman and Steyn, 2003). However, some of these methods are either expensive, inefficient or not user-friendly. With the world economic meltdown, no country is spared, and

\footnotetext{
* To whom all correspondence should be addressed.

용 +2712 3823533; fax: +27123823532 ; e-mail: OnyangoMS@tut.ac.za

Received 2 December 2009; accepted in revised form 3 September 2010.
}

thus countries are emphasising reducing costs as well as developing technologies which add value to the lives of people. It is therefore necessary to screen techniques to find which ones suit rural communities such as those of South Africa. In doing so, a number of factors that form the basis of a decision framework are considered. These factors include: cost, regulatory compliance and public perception and acceptance. For these reasons, a technique based on adsorption processes is an attractive alternative for rural communities (Onyango and Matsuda, 2006).

The removal of anionic contaminants from water by adsorption methods has been widely studied in recent years. Interest is growing in the use of natural materials, due to their cost implication. One such material is zeolite (Bowman et al., 2000; Ranck, 2005). Zeolites are synthetic or naturallyoccurring hydrated alumino silicates with a cage-like structure, high external cationic exchange capacity and high surface area. The structural framework of zeolite is negatively charged due to isomorphic substitution of aluminium for silicon (Onyango, 2006). Thus, loading anionic contaminants like nitrates onto its surface is only negligibly possible, due to coulumbic repulsive forces (Kumar et al., 2006). Therefore, to render the zeolite suitable for anionic contaminant removal from water, its surface charge property must be altered using appropriate charge reversing chemical species (Onyango et al., 2004). While some researchers have utilised synthetic zeolites for water treatment, in this study we exploit the readily available and cheaper natural clinoptilolite from the Western Cape area of South Africa. There is hardly any information in literature on the use of this zeolitic tuff in purifying water containing health-hazardous anions such as nitrate. The study aims to demonstrate the performance of this material in nitrate removal from water, with respect to surfactant loading, adsorbent dosage, $\mathrm{pH}$, coexisting 


\begin{tabular}{|l|l|c|}
\hline \multicolumn{3}{|c|}{$\begin{array}{c}\text { Table } 1 \\
\text { Summary of adsorption equilibrium and kinetic } \\
\text { models }\end{array}$} \\
\hline Model & Equation & No. \\
\hline \multirow{2}{*}{ Freundlich } & $\mathrm{q}_{\mathrm{e}}=\mathrm{K}_{\mathrm{f}} \mathrm{C}_{\mathrm{e}}^{1 / \mathrm{n}}$ & $(1)$ \\
\cline { 2 - 3 } & $\ln \mathrm{q}_{\mathrm{e}}=\ln \mathrm{K}_{\mathrm{f}}+1 / \mathrm{n} \ln \mathrm{C}_{\mathrm{e}}$ & $(2)$ \\
\hline \multirow{2}{*}{ Langmuir } & $\mathrm{q}_{\mathrm{e}}=\mathrm{q}_{\mathrm{o}} \mathrm{bCe} /\left(1+\mathrm{b} \mathrm{C}_{\mathrm{e}}\right)$ & $(3)$ \\
\cline { 2 - 3 } $\mathrm{C}_{\mathrm{e}} / \mathrm{q}_{\mathrm{e}}=1 / \mathrm{q}_{\mathrm{o}} \mathrm{b}+\mathrm{C}_{\mathrm{e}} / \mathrm{q}_{\mathrm{o}}$ & $(4)$ \\
\hline $\begin{array}{l}\text { Pseudo-first order } \\
\text { (linear form) }\end{array}$ & $\ln \left(\mathrm{q}_{\mathrm{e}}-\mathrm{q}_{\mathrm{t}}\right)=\ln \mathrm{q}_{\mathrm{e}}-\mathrm{k}_{1} \mathrm{t}$ & $(5)$ \\
\hline $\begin{array}{l}\text { Pseudo-second order } \\
\text { (linear form) }\end{array}$ & $\mathrm{t} / \mathrm{q}_{\mathrm{t}}=1 / \mathrm{k}_{2} \mathrm{q}_{\mathrm{e}}^{2}+\mathrm{t} / \mathrm{q}_{\mathrm{e}}$ & $(6)$ \\
\hline
\end{tabular}

Note: $K_{f}$ and $b$ are Freundlich and Langmuir constants, respectively, $q_{e}$ is the uptake at equilibrium $\left(\mathrm{mg} \cdot \mathrm{g}^{-1}\right), C_{e}$ is the equilibrium concentration $\left(m g \cdot \ell^{-1}\right), q_{o}$ is the theoretical adsorption capacity $\left(\mathrm{mg} \cdot \mathrm{g}^{-1}\right), 1 / \mathrm{n}$ is the heterogeneity coefficient, $k_{1}\left(\ell \cdot \mathrm{min}^{-1}\right)$ is the pseudo-first order rate constant, $k_{2}\left(g \cdot \mathrm{mg}^{-1} \mathrm{~min}^{-1}\right)$ is the pseudo-second order rate constant, $q_{t}\left(\mathrm{mg}^{2} \cdot \mathrm{g}^{-1}\right)$ is the amount of nitrate adsorbed at time t (min).

ions, temperature and environmental water quality. The nitrate percentage removal and the ability to meet the local regulatory compliance are used as performance indicators. Equilibrium and kinetic modelling are done to estimate important capacity and rate parameters which can aid in system design.

\section{Equilibrium and kinetic models}

The analysis and design of an adsorption process requires information on the equilibrium adsorption isotherms and rate data. Moreover, the evaluation of the equilibrium data also helps in the investigation of mechanisms involved in nitratezeolite interaction. In this work, the 2 adsorption equilibrium models used are the Freundlich and Langmuir isotherms. Altin et al. (1998) indicated that the Langmuir and the Freundlich adsorption isotherms are the most widely used mathematical models, owing to their simplicity and ability to describe liquidphase equilibrium data in a wide range of concentrations. For brevity, a summary of the isotherm models are given in Table 1. The theoretical basis of these isotherms is readily available in the literature.

Theoretically, an adsorbing species may occupy 1 or 2 adsorption sites. The kinetics of the former sorbate-sorbent interaction is described by the Lagergren pseudo-first order model (Uysal and Ar, 2007) while the latter is described by the Ho pseudo-second order model (Ho and McKay, 1999). Table 1 summarises the linearised pseudo-first order model (Eq. (5)) and pseudo-second order model (Eq. (6)) used in interpreting the kinetic data.

\section{Experimental}

\section{Preparation of surfactant-modified natural zeolite.}

The natural zeolite used in this study was clinoptilolite supplied by Interscan Company, South Africa. The material was thoroughly washed with deionised water to remove dirt. Washed zeolite was then allowed to dry. To convert the zeolite to a final homoionic or near homoionic state, $20 \mathrm{~g}$ of the natural zeolite was treated with $2 \mathrm{M} \mathrm{NaCl}$ solution at room temperature over a period of $3 \mathrm{~d}$. The solution was kept under agitation on a shaker operated at $200 \mathrm{r} \cdot \mathrm{min}^{-1}$. After $3 \mathrm{~d}$ the solution was vacuum filtered and the conditioned zeolite prepared as such was double-washed with deionised water to remove excess sodium chloride. The conditioned zeolite ( $\mathrm{Na}$ form) was then dried at $105^{\circ} \mathrm{C}$ for $24 \mathrm{~h}$.

Hexadecyltrimethyl ammonium bromide (HDTMABr) from Sigma Aldrich, South Africa, was used for surface modification. A pre-weighed quantity of conditioned zeolite sample was mixed with HDTMABr solution in 1:100 (solid: liquid) ratio. The concentrations of HDTMABr used for the preparation of surfactant modified zeolite (SMZ) were $1 \mathrm{~g} \cdot \ell^{-1}, 2 \mathrm{~g} \cdot \ell^{-1}$, $3 \mathrm{~g} \cdot \ell^{-1}$ and $4 \mathrm{~g} \cdot \ell^{-1}$. The zeolite and surface-modifying solution were contacted in a batch reactor for $3 \mathrm{~d}$. Finally, the solution was vacuum filtered, and the solid residue was double-washed with deionised water and air dried. The materials prepared in this manner are hereafter referred to as SMZ1 (for $1 \mathrm{~g} \cdot \ell^{-1} \mathrm{HDTMABr}$ ), SMZ2 (for $2 \mathrm{~g} \cdot \ell^{-1}$ HDTMABr), SMZ3 (for $3 \mathrm{~g} \cdot \ell^{-1} \mathrm{HDTMABr}$ ) and SMZ4 (for $4 \mathrm{~g} \cdot \ell^{-1} \mathrm{HDTMABr}$ ).

\section{Adsorption media characterisation}

Fourier transform infrared (FTIR) spectroscopy analyses were undertaken on a Perkin Elmer Spectrum 100 spectrophotometer. The FTIR spectrum of the solid sample dispersed in $\mathrm{KBr}$ disk was obtained to determine the functional groups in the surfactant-modified zeolite (SMZ) and HDTMA. The spectrum was recorded in the region from 500 to $4000 \mathrm{~cm}^{-1}$ with a spectra resolution of $4 \mathrm{~cm}^{-1}$.

\section{Nitrate adsorption experiments}

The nitrate adsorption experiments were conducted using environmental water from Limpopo Province and assimilated water samples of known initial concentration prepared by dissolution of an appropriate amount of $\mathrm{KNO}_{3}$ (analytical grade) and performance of the necessary dilution. Batch experimental mode was adopted due to its simplicity. In the $1^{\text {st }}$ set of experiments, $50 \mathrm{~m} \ell$ nitrate solutions contained in $100 \mathrm{~m} \ell$ plastic bottles were contacted with $0.5 \mathrm{~g}$ of unmodified natural zeolite and $\mathrm{SMZ}$ samples. The sealed bottles containing $50 \mathrm{mg} \cdot \ell^{-1}$ nitrate solution were placed in a thermostatic shaker operated at 200 $\mathrm{r} \cdot \mathrm{min}^{-1}$ for $24 \mathrm{~h}$ at $20^{\circ} \mathrm{C}$. After $24 \mathrm{~h}$ the samples were filtered through a Whatman Filter Paper No. 41. The filtrate was then analysed for residual nitrate concentration. The nitrate percentage removal was calculated from:

$$
\% \text { removal }=100 \frac{\left(C_{o}-C_{e}\right)}{C_{o}}
$$

where $C_{\mathrm{o}}\left(\mathrm{mg} \cdot \ell^{-1}\right)$ is the initial nitrate concentration and $C_{\mathrm{e}}$ $\left(\mathrm{mg} \cdot \ell^{-1}\right)$ is the concentration of nitrate at equilibrium. In a $2^{\text {nd }}$ second set of experiments, the effects of $\mathrm{pH}$ and temperature on nitrate removal from water were explored by varying the initial solution $\mathrm{pH}$ from 1.66 to 11 and temperature from 20 to $60^{\circ} \mathrm{C}$. The other experimental conditions were unchanged. Meanwhile the adsorption isotherm data were generated by contacting SMZ (0.5 g each) with nitrate solution in the concentration range from 10 to $300 \mathrm{mg} \cdot \ell^{-1}(50 \mathrm{~m} \ell$ each) for $24 \mathrm{~h}$ in a thermostatic shaker operated at $200 \mathrm{r} \cdot \mathrm{min}^{-1}$. The equilibrium adsorption capacity was obtained by:

$$
q_{\mathrm{e}}=\left(C_{\mathrm{o}}-C_{\mathrm{e}}\right) V / m
$$

where $q_{\mathrm{e}}\left(\mathrm{mg} \cdot \mathrm{g}^{-1}\right)$ is the equilibrium adsorption capacity, $V(\ell)$ is the volume of the solution and $m(\mathrm{~g})$ is the mass of the SMZ. Since natural water contains different anions in different concentrations, which may compete with nitrates for the 
available active sites, it is therefore imperative to study their effect on nitrate removal from water. The effects of the presence of sulphate, fluoride, phosphate and chloride on nitrate adsorption were studied. Tests were conducted in the presence of 10 $\mathrm{mg} \cdot \ell^{-1}$ of nitrate and $10 \mathrm{mg} \cdot \ell^{-1}$ each of the co-existing ions. The adsorbent mass was fixed at $0.1 \mathrm{~g}$ per $50 \mathrm{~m} \ell$ solution. The experimental procedure was similar to that described previously. In the kinetic experiments, the effect of particle size on nitrate adsorption was studied. The particle sizes used were: $<75 \mu \mathrm{m}, 150-300$ $\mu \mathrm{m}$ and 300-600 $\mu \mathrm{m}$. The sorbent was contacted with nitratecontaining $\left(100 \mathrm{mg} \cdot \ell^{-1}\right)$ aqueous solution for a period between 0 and $60 \mathrm{~min}$. A final set of experiments involved the use of natural groundwater samples collected from various locations of Limpopo Province. The samples were analysed for nitrate levels before contacting them with different masses of sorbents. The equilibrium nitrate concentration was determined after $24 \mathrm{~h}$.

\section{Analysis of nitrate}

The determination of nitrate in the filtrate followed the salicylate method (Monteiro et al., 2003). The absorbance of the solutions was measured at $410 \mathrm{~nm}$ using a UV visible spectrophotometer (Hach DR/3000).

\section{Results and discussion}

\section{Zeolite characterisation}

The raw zeolite used in this study was first conditioned with $\mathrm{Na}^{+}$salt with the aim of removing certain cations from the structure and locating more easily removable ones, prior to any ion exchange application. It has been shown that the final homoionic or near homoionic state after conditioning zeolite improves the effective exchange capacity (Hui et al., 2005; Inglezakis, 2005; Athanasiadis and Helmreich, 2005). An FTIR study was used to explore changes in chemical stability and composition of the zeolite following conditioning and functionalisation. The FTIR patterns of raw, conditioned, surfactantmodified and nitrate-containing zeolites are shown in Fig. 1a. The raw zeolite and the zeolite in homoionic state (conditioned) show characteristic peaks at wave-numbers $624,808,993$ and $1594 \mathrm{~cm}^{-1}$. Upon functionalisation of zeolite, new bands are observed at 1461,2848 and $2915 \mathrm{~cm}^{-1}$, which can be attributed to HDTMA sorbed on the external surface of the zeolite, as the corresponding peaks are also observed in the FTIR pattern of HDTMA (see Fig. 1b). Nitrate adsorption on functionalised zeolite caused the bands at positions 1461, 2848 and 2915 $\mathrm{cm}^{-1}$ to decrease in intensity suggesting that the active sites created by HDTMA were responsible for nitrate removal from water. This observation corroborated the fact that the nitrate adsorption was of a physical nature, probably due to electrostatic forces between positively charged surfactant-modified zeolite and anionic nitrates. Most band positions did not change following modification and adsorption, suggesting that the basic zeolite structure did not collapse.

\section{Optimising surfactant loading on zeolite with respect to nitrate adsorption}

Nitrate is an outer-sphere complex-forming species and therefore its ample removal from water by adsorption is a challenge. In order to apply conventional adsorption media, their surfaces need to be modified to induce functional groups that can attract and adsorb nitrate ions. Recently, surfactants have been widely

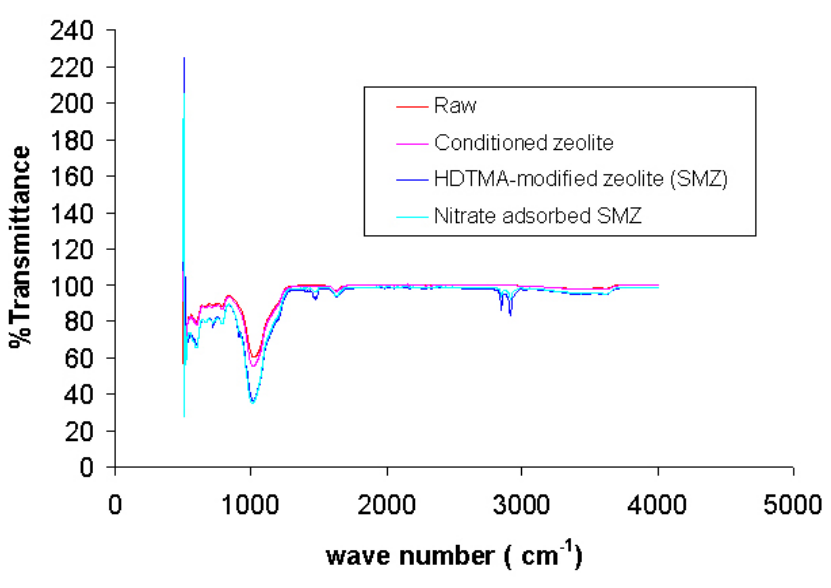

Figure 1a

The FTIR spectra of raw, conditioned, modified, and nitrate-adsorbed zeolites
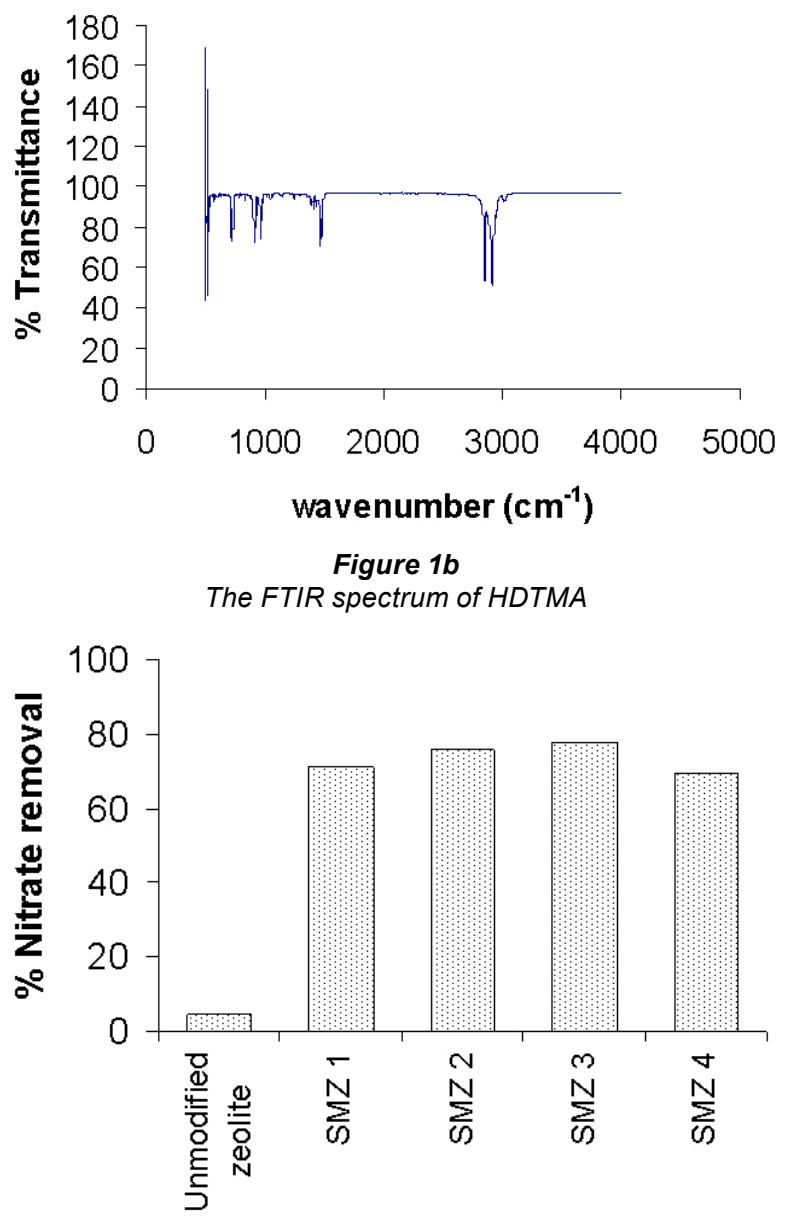

Figure 2

Sorption of nitrate on raw and surfactant modified zeolites. Initial nitrate concentration $=50 \mathrm{mg} / \ell$; sorbent mass $=0.5 \mathrm{~g}$; particle size $=150-300 \mu \mathrm{m} ;$ equilibrium time $=24 \mathrm{~h}$

reported to aid adsorption of anions. Consequently, this study considers the use of positively-charged HDTMA as the surfacemodifying surfactant. Several studies have been reported on the use of HDTMA in modifying different kinds of adsorption media (Zhou et al., 2008; Wingenfelder et al., 2006; Yusof et al., 2009). Figure 2 shows the application of unmodified zeolite and surfactant-modified zeolites in nitrate removal from water. 
The results clearly show that unmodified zeolite has very litthe adsorption capacity for nitrates. This observation concurs well with those of previous researchers (Schick et al., 2010; Mažeikienè et al., 2008; Li and Bowman, 2001). Zeolites are not good candidates for removal of anions from water because of their inherently negatively-charged surfaces that increase coulombic repulsion between the adsorbing anionic species and active sites. When the zeolite was functionalised with HDTMA (SMZ1, SMZ2, SMZ3, SZM4), a remarkable nitrate removal was observed. Surfactant modification of zeolite (clinoptilolite in this case) changes its surface charge from a net negative to a positive charge. Thus, electrostatic forces exist between the positively-charged zeolite and the nitrates in solution, which enhance nitrate adsorption. The nitrate removal increases with an increase in the concentration of the functionalising HDTMA and a value of $3 \mathrm{~g}$ HDTMA $\cdot \ell^{-1}$ gives the best performance. Further increase of HDTMA concentration to $4 \mathrm{~g} \cdot \ell^{-1}$ results in a decline in removal of nitrates. This may be due to the fact that $4 \mathrm{~g} \cdot \ell^{-1}$ exceeds the surfactant critical micelle concentration; thus the micelles attach to the external surface of the zeolite and rearrange to form a bi-layer that tends to impart anionic characteristics (Bowman et al., 2000). Therefore, zeolite treated with an initial concentration of $3 \mathrm{~g} \cdot \ell^{-1}$ (SMZ3) of the surfactant appears to give optimal results and was used in all subsequent experiments.

\section{Effect of co-existing anions}

In reality the nitrate-contaminated water contains several other anions which can compete for the same adsorption sites. In order to explore the effect of interfering anions on the nitrate removal ability of the SMZ3, binary component systems were adopted in which nitrate removal in the presence of another anionic species was studied. The anions considered in this study included; phosphate, sulphate, chloride and fluoride. These anions represent both inner-sphere (phosphate and fluoride) and outer-sphere (sulphate and chloride) complexforming species. The nitrate percentage removal of SMZ3 for single component (nitrate only) and in the presence of other anions is shown in Fig. 3. In the $\mathrm{NO}_{3}^{-}$single component system, the nitrate percentage removal is $99 \%$. This value reduces to $90 \%$ in the $\mathrm{NO}_{3}^{-} / \mathrm{PO}_{4}{ }^{3-}$ binary component system. The binary systems involving sulphate, chloride and fluoride give $95 \%$, $98 \%$ and $99 \%$ nitrate removal, respectively. Similar observations were recently reported by Saad et al. (2007) and Öztürk and Bektaş (2004). The trend in nitrate removal in the presence of coexisting anions seems to be related to the valence of the coexisting anions. Trivalent phosphate has the largest effect while monovalent anions give the least effect. These results suggest that electrostatic coulombic interaction plays a major role in nitrate uptake.

\section{Effect of adsorbent mass}

The number of active sites relates to adsorbent mass and hence sorption performance. The effect of adsorbent mass on the nitrate percentage removal is shown in Fig. 4. It is clear that an increase in adsorbent mass resulted in an increase in the removal of nitrates from water. Specifically, nitrate removal increases from $25 \%$ when the sorbent mass is $0.1 \mathrm{~g} \cdot(50 \mathrm{~m} \ell)^{-1}$ to $100 \%$ when the sorbent mass is $1.5 \mathrm{~g} \cdot(50 \mathrm{~m} \ell)^{-1}$, due to an increase in available sorption sites. However, it is observed that the increase in nitrate percentage removal is not directly proportional to adsorbent mass. One plausible reason could be due

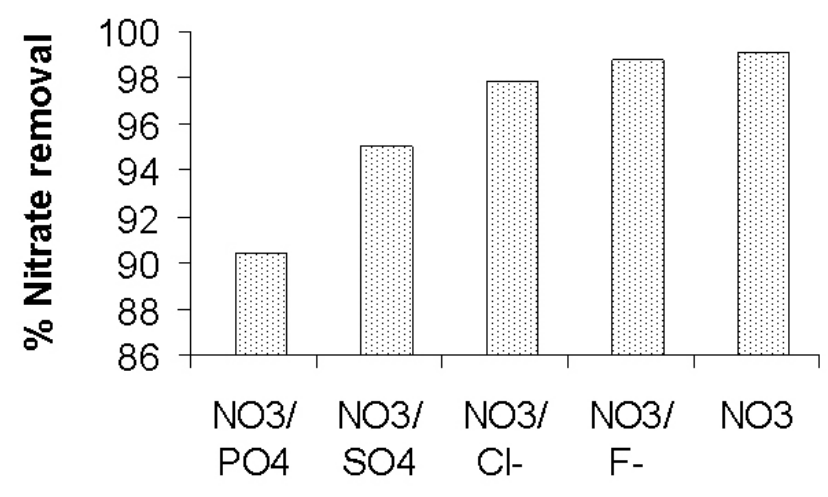

\section{Binary component systems}

Figure 3

Effect of coexisting anions on nitrate removal from water. Sorbent mass $=0.1 \mathrm{~g}$; initial nitrate concentration $=10 \mathrm{mg} / \mathrm{\ell}$; particle size $=150-300 \mu \mathrm{m}$; equilibrium time $=24 \mathrm{~h}$

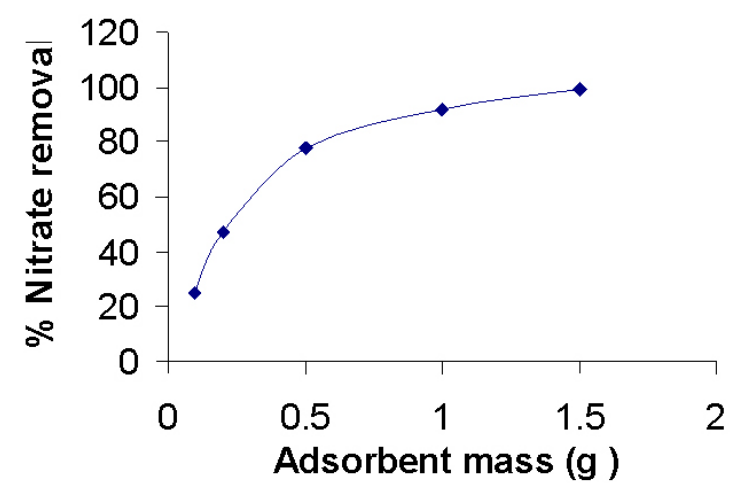

Figure 4

Effect of adsorbent mass on nitrate removal by SMZ3. Initial nitrate concentration $=50 \mathrm{mg} / \mathrm{\ell}$; particle size $=150-300 \mu \mathrm{m}$; equilibrium time $=24 \mathrm{~h}$

to overlap of active sites at higher adsorbent masses resulting in reduced effective surface area required for sorption.

\section{Effect of $\mathrm{pH}$}

Solution $\mathrm{pH}$ is one of the factors that have been found to significantly affect the sorption process (Onyango et al., 2006). A study was therefore undertaken to ascertain to what extent $\mathrm{pH}$ affected the sorption of nitrate. Table 2 summarises the effects of initial solution $\mathrm{pH}$ (1.6-11) on the removal of nitrate from water. The system (solution-solid) $\mathrm{pH}$ at equilibrium is also included. Results reveal that nitrate removal from water is marginally affected by $\mathrm{pH}$. With no electrokinetic data at this stage, it can only be hypothesised that the surface charge on the SMZ3 was not significantly affected by $\mathrm{pH}$ changes. A confirmation is required to ascertain this. The slight decrease in nitrate adsorption with increase in $\mathrm{pH}$ could be due to interaction during passive transport in the pores and competition between $\mathrm{OH}^{-}$and $\mathrm{NO}_{3}^{-}$anions for active sites. One disadvantage of using adsorption processes in removal of anionic contaminants from water inheres in most sorption media's inability to perform adequately at higher $\mathrm{pH}$. Indeed several researchers have reported a significant reduction in media performance in nitrate removal from water at near neutral and alkaline $\mathrm{pH}(6.5-8.5)$, the $\mathrm{pH}$ range typical of natural systems such as 


\begin{tabular}{|c|c|c|}
\hline \multicolumn{3}{|c|}{$\begin{array}{c}\text { Table 2 } \\
\text { Effect of } \\
\text { pH on nitrate removal } \\
\text { from water }\end{array}$} \\
\hline Initial pH & Final pH & Removal (\%) \\
\hline 1.66 & 2.04 & 100 \\
\hline 4.66 & 6.71 & 99.2 \\
\hline 6.56 & 7.23 & 98.2 \\
\hline 8.47 & 7.61 & 96.0 \\
\hline 11.0 & 9.87 & 96.0 \\
\hline
\end{tabular}

groundwater (Chatterjee et al., 2009; Chatterjee and Woo, 2009; Cengeloglu et al., 2006). A media, such as SMZ3 used in this study, whose performance does not deteriorate with $\mathrm{pH}$ changes is desirable for water treatment. Meanwhile the $\mathrm{pH}$ of the system (solution-solid) after sorption was found to increase when the initial $\mathrm{pH}$ was acidic and to decrease when the initial $\mathrm{pH}$ was alkaline. This is due to the buffering effect of the zeolite. Sorbents normally shift solution $\mathrm{pH}$ towards their natural $\mathrm{pHs}$ or their point-of-zero charge $\left(\mathrm{pH}_{\mathrm{pzc}}\right)$ (Onyango, 2006).

\section{Effect of temperature}

The effect of temperature was investigated in a range of $20-60^{\circ} \mathrm{C}$ and is shown in Fig. 5. It was observed that an increase in temperature resulted in a minor decrease in nitrate uptake by SMZ3. This clearly indicates that the adsorption process was exothermic. Similar observations in which adsorption decreased with an increase in temperature were recently reported by Chatterjee and Woo (2009) for nitrate adsorption by chitosan hydrogel beads. Temperature may or may not have a significant effect on adsorption depending on whether the process is chemical or physical in nature. When the process is chemical in nature, a higher energy barrier has to be overcome and hence temperature changes result in a significant (either a large increase or large decrease in adsorption) effect on adsorption. Conversely, a minor effect is normally observed when the process is physical in nature. The results of this study therefore reveal further that the nitrate adsorption process is physical in nature, involving coulombic electrostatic forces between the positively-charged SMZ3 surface and negatively-charged nitrate ion.

\section{Adsorption isotherm}

The design of an adsorption system requires equilibrium isotherm data. This study considers the application of the 2 most commonly-used isotherms: the Freundlich (Eq. (1) and linear form Eq. (2) and Langmuir (Eq. (3) and linear form Eq. (4)) models. The Langmuir isotherm is based on the premise that all active sites have identical energy strength. Figure 6 shows a typical fit of linearised Langmuir isotherm (see Table 1, Eq. (4)) for the experimental data $\left(\right.$ at $\left.20^{\circ} \mathrm{C}\right)$ presented in Fig. 5. There is a deviation from linearity in the low concentration range. The regression coefficient $\left(R^{2}\right)$ is 0.973 . The $R^{2}$ values for other temperatures, $45^{\circ} \mathrm{C}$ and $60^{\circ} \mathrm{C}$, are 0.957 and 0.913 , respectively, which, for physico-chemical process like adsorption, are not very high. The Langmuir parameters, $q_{\mathrm{o}}$ and $b$, were determined from the slope and intercept of the plots, and are 12.35 $\mathrm{mg} \cdot \mathrm{g}^{-1}$ and $0.048 \ell \cdot \mathrm{mg}^{-1}$, respectively. The Langmuir parameters for other temperatures are summarised in Table 3 . The $q_{\mathrm{o}}$ value is sufficiently high for a class of low-cost natural materials but lower than that of high-cost synthetic materials (Chatterjee

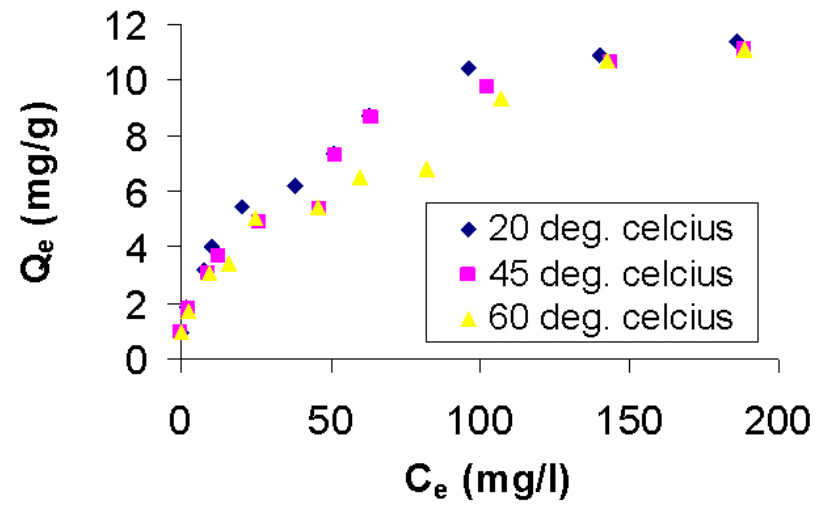

Figure 5

Effect of temperature on nitrate removal by SMZ3

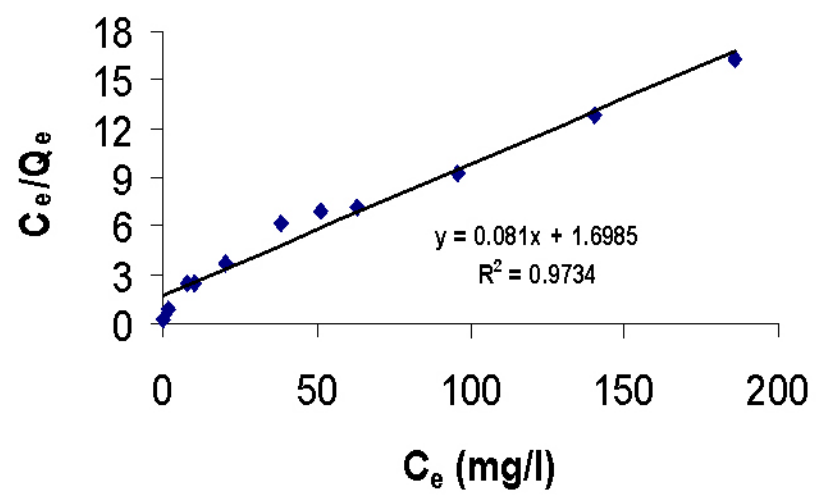

Figure 6

Linearised Langmuir isotherm (Eq. (4)) for nitrate adsorption onto SMZ3. Temp. $=20^{\circ} \mathrm{C} ; \mathrm{pH}=6.6$; adsorbent dose $=0.5 \mathrm{~g}$; particle size $=150-300 \mu \mathrm{m}$

and Woo, 2009; Chatterjee et al., 2009). The feasibility of the Langmuir isotherm was assessed using dimensionless constant separation factor, $R_{L}$, defined by:

$$
R_{L}=1 /\left(1+\mathrm{bC}_{\mathrm{o}}\right)
$$

where $b$ is the Langmuir constant and $C_{\mathrm{o}}$ is the initial nitrate concentration (mg. $\left.\ell^{-1}\right)$. The value of $R_{L}$ indicates whether the isotherm is irreversible $\left(R_{L}=0\right)$, favourable $\left(0<R_{L}<1\right)$, linear $\left(R_{L}=1\right)$ or unfavourable $\left(R_{L}>1\right)$. $R_{\mathrm{L}}$ values between 0 and 1 were obtained suggesting the present sorption system is favourable.

The Freundlich isotherm, which describes sorption on sites of different affinity for sorbate, was applied in the linear form

\begin{tabular}{|c|c|c|c|}
\hline \multicolumn{4}{|c|}{$\begin{array}{c}\text { Table } 3 \\
\text { Summary of adsorption isotherm parameters }\end{array}$} \\
\hline Parameters & $20^{\circ} \mathrm{C}$ & $45^{\circ} \mathrm{C}$ & $60^{\circ} \mathrm{C}$ \\
\hline \multicolumn{4}{|c|}{ Langmuir isotherm } \\
\hline$q_{0}\left(\mathrm{mg} \cdot \mathrm{g}^{-1}\right)$ & 12.35 & 12.09 & 12.21 \\
\hline$b\left(\ell \cdot \mathrm{mg}^{-1}\right)$ & 0.0477 & 0.0366 & 0.0298 \\
\hline$R^{2}$ & 0.97 & 0.95 & 0.91 \\
\hline \multicolumn{4}{|c|}{ Freundlich isotherm } \\
\hline$K_{\mathrm{F}}$ & 1.59 & 1.44 & 1.12 \\
\hline$n$ & 2.55 & 3.05 & 2.31 \\
\hline$R^{2}$ & 0.99 & $>0.98$ & 0.98 \\
\hline
\end{tabular}




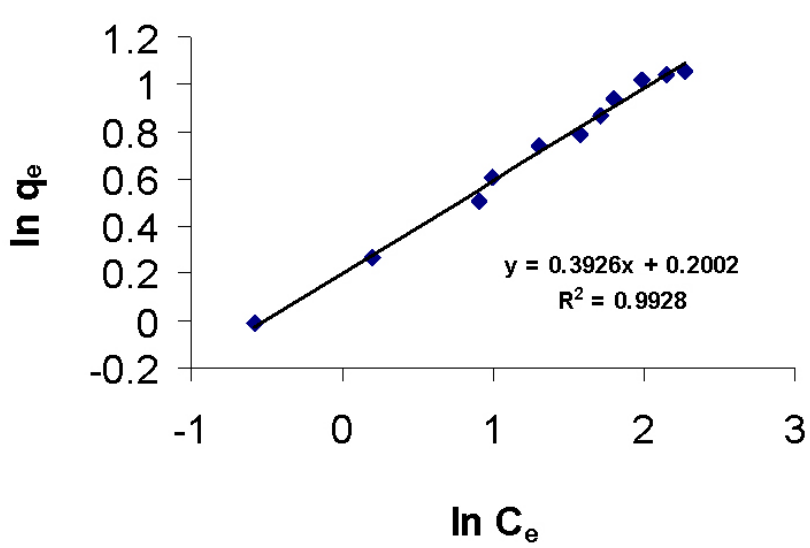

Figure 7

Linearised Freundlich isotherm (Eq. (2)) for nitrate adsorption onto SMZ3. Temp. $=20^{\circ} \mathrm{C} ; \mathrm{pH}=6.6$; adsorbent dose $=0.5 \mathrm{~g}$; particle size $=150-300 \mu m$

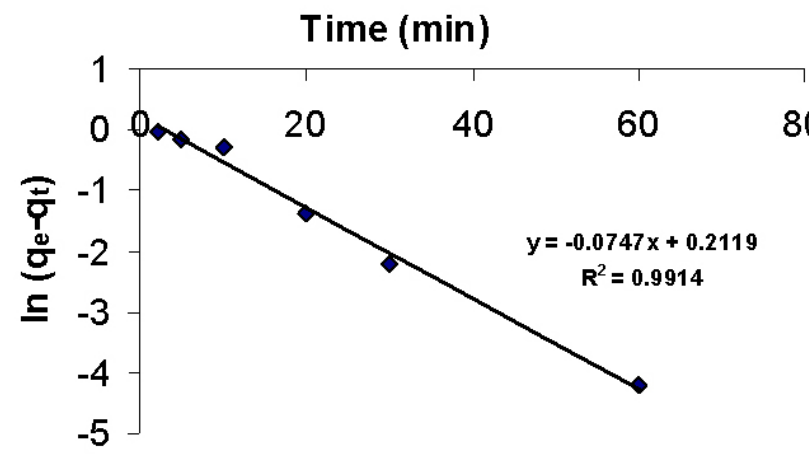

Figure 8

Fit of experimental data according to pseudo-first order kinetic model

expressed by Eq. (2) and is presented in Fig. 7. Linear plots were obtained with $R^{2}$ in the range $0.98-0.99$, suggesting a good description of isotherm data by this model. In a study of nitrate removal from water by ion exchange resin, Chabani et al. (2006) also found the Freundlich isotherm to give the best description of the equilibrium data. The Freundlich constants, $K_{\mathrm{f}}$ and $n$, calculated at $20^{\circ} \mathrm{C}$ from this investigation, are 1.59 and 2.55 , respectively. Values of $n$ greater than 1 indicate favourable adsorption (Chabani et al., 2006). The Freundlich parameters for all the temperatures investigated are summarised in Table 3.

\section{Adsorption kinetics}

To apply an adsorption process for large-scale treatment of water, a clear understanding and determination of the rate parameters is a prerequisite. Kinetic data can be used to determine the time required for sorption to go to equilibrium and to develop predictive models that can aid in system design. Two kinetic models summarised in Table 1 were used to fit the experimental data. The first was the Lagergren pseudo-first order model (Eq. (5)). A plot of $\ln \left(q_{\mathrm{e}}-q_{\mathrm{t}}\right)$ versus $t$ according to Eq. (5) should be linear if the adsorption process follows the first order kinetics. The equilibrium uptake in this case was used as a fitting parameter. For 150-300 $\mu \mathrm{m}$ sorbent size, the fitting value of $q_{\mathrm{e}}=11.53 \mathrm{mg} \cdot \mathrm{g}^{-1}$ was used. A typical plot according to Eq. (5) is presented in Fig. 8 for particle size

\begin{tabular}{|c|c|c|c|}
\hline \multicolumn{4}{|c|}{$\begin{array}{c}\text { Table } 4 \\
\text { Summary of adsorption kinetic parameters }\end{array}$} \\
\hline Parameters & $<75 \mu \mathrm{m}$ & $150-300 \mu \mathrm{m}$ & $300-600 \mu \mathrm{m}$ \\
\hline \multicolumn{4}{|c|}{ Pseudo-first order kinetics } \\
\hline$k_{1}\left(\min ^{-1}\right)$ & 0.075 & 0.075 & 0.025 \\
\hline$q_{\mathrm{e}}\left(\mathrm{mg} \cdot \mathrm{g}^{-1}\right)$ & 1.475 & 1.236 & 3.934 \\
\hline $\mathrm{R}^{2}$ & 0.945 & 0.991 & 0.828 \\
\hline \multicolumn{4}{|c|}{ Pseudo-second order kinetics } \\
\hline $\begin{array}{l}k_{2} \\
\left(\mathrm{~g} \cdot \mathrm{mg}^{-1} \mathrm{~min}^{-1}\right)\end{array}$ & 0.174 & 0.183 & 0.048 \\
\hline$q_{\mathrm{e}}\left(\mathrm{mg} \cdot \mathrm{g}^{-1}\right)$ & 11.40 & 11.43 & 10.48 \\
\hline $\mathrm{R}^{2}$ & $>0.999$ & $>0.999$ & $>0.999$ \\
\hline
\end{tabular}

150-300 $\mu \mathrm{m}$. The curve is linear with regression coefficient $R^{2}>0.99$. From the linear curve a rate constant $k_{1}$ was determined from the slope and is $0.075 \mathrm{~min}^{-1}$. The first order rate constant, $k_{1}$, is in the same order of magnitude for sorbent size $<75 \mu \mathrm{m}$ and $150-300 \mu \mathrm{m}$ (see Table 4), but significantly lower in magnitude for sorbent size $300-600 \mu \mathrm{m}$. The latter is attributed to reduced external surface area for reaction and at the same time may be due to the increased diffusion path - a species has to travel a longer distance to reach an active site. Apparently, in adsorption, diffusive transport has an effect on the overall kinetics of the process. The nitrate uptake at equilibrium was determined from the intercept and is only $1.236 \mathrm{mg} \cdot \mathrm{g}^{-1}$. The $q_{\mathrm{e}}$ extracted from the intercept is extremely low and does not match the one used as fitting parameter. Hence the pseudo-first order model is not applicable to the present sorption system.

The linear form of Ho pseudo-second order model, Eq. (6), was tested as a plot of $t / q_{\mathrm{t}}$ versus $t$ and is shown in Fig. 9. From the value of the regression coefficient, $R^{2}>0.99$, it can be concluded that the pseudo-second order model describes the nitrate kinetic data. This observation is in total agreement with that of previous researchers (Özturk and Bektas, 2004). The calculated values of $q_{\mathrm{e}}$ and $k_{2}$ are $11.43 \mathrm{mg} \cdot \mathrm{g}^{-1}$ and $0.183\left(\mathrm{~g} \cdot \mathrm{min}^{-1} \mathrm{mg}^{-1}\right)$, respectively. In this case, the calculated $q_{\mathrm{e}}$ value is almost the same as the experimental value and only marginally decreases with sorbent size. This observation is not surprising as sorption active sites are not normally dependent on sorbent size. As a rule, the pseudo-second order kinetic model describes sufficiently the nitrate adsorption kinetic data. As with the case of pseudo-first order kinetics, the rate constant, $k_{2}$, is in the same order of magnitude for sorbent size $<75 \mu \mathrm{m}$ and 150-300 $\mu \mathrm{m}$ (see Table 4), but is significantly lower in magnitude for sorbent size $300-600 \mu \mathrm{m}$.

\section{Application of SMZ to nitrate removal from groundwater}

Many rural communities in South Africa use groundwater for drinking purposes. With increased spells of drought leading to water scarcity, groundwater may form a major source of potable water in the near future. However, nitrate concentrations in some of the groundwater sources used for drinking purposes are above the limit of $50 \mathrm{mg} \cdot \ell^{-1}$ (see Fig. 10), the maximum recommended by WHO. In this study, ability of SMZ3 to remove nitrate from environmental water (groundwater) was explored. The water samples were collected from 3 areas, Tshiozwi, Lesodi Motlala and Sekhokho, all in Limpopo Province. The residual nitrate concentration for the 3 water samples as a function of sorbent mass is shown in Fig. 10. First, an increase in sorbent mass resulted in an increased removal of nitrate 


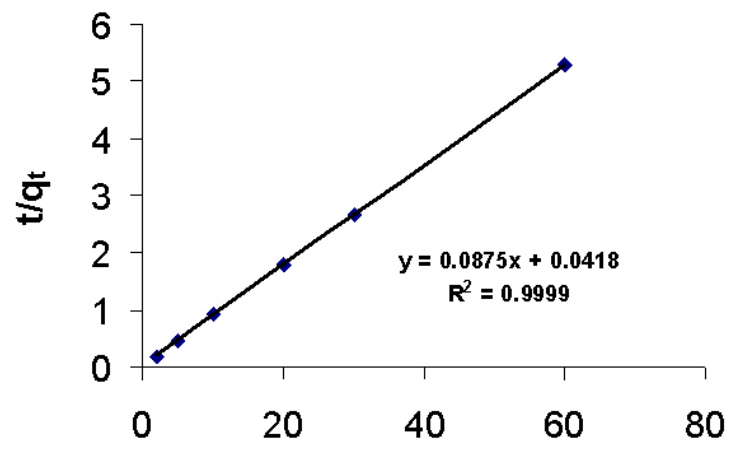

Time ( $\min )$

Figure 9

Fit of experimental data according to pseudo-second order kinetic model

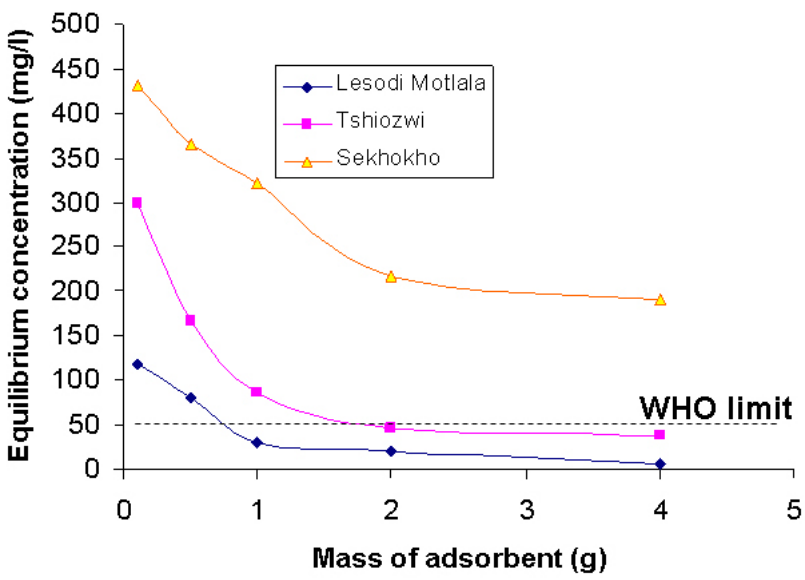

Figure 10

Effect of sorbent mass on nitrate removal from South African groundwater samples

from groundwater samples. This is attributed to increased sorption sites in the media. Second, at sorbent mass above $2 \mathrm{~g}$, the residual concentration of nitrate in Chiozi and Lesodi Motlala water samples was below $50 \mathrm{mg} \cdot \ell^{-1}$, while the nitrate level in Sekhokho water was still above the maximum allowable concentration (MAC) value. The latter is attributed to the extremely high level of initial concentration. Such high levels of nitrate in water may require combined systems for effective removal.

\section{Conclusions}

HDTMA was successfully used to functionalise clinoptilolite and it was demonstrated that the latter is a low-cost and robust media for nitrate removal from water. The functionalised zeolite (SMZ) exhibited a nitrate maximum adsorption capacity of around $11.4 \mathrm{mg} \cdot \mathrm{g}^{-1}$, which is sufficiently high for this class of natural media. The SMZ can be efficiently used over a wide range of temperature and $\mathrm{pH}$ without a significant change in performance. Hence, nitrate-SMZ interaction seems to be physical in nature, probably involving coulombic electrostatic forces. In binary component systems, nitrate sorption was marginally affected by the presence of co-ions. Meanwhile the equilibrium data were satisfactorily described by the Freundlich isotherm while the kinetic data fitted well to the pseudo-second order kinetic model. Results from application of SMZ to treatment of environmental water suggest that the maximum allowable concentration of $50 \mathrm{mgNO}_{3} \cdot \ell^{-1}$ is achievable even when the initial nitrate concentration exceeds $300 \mathrm{mg} \cdot \ell^{-1}$. With South Africa being a water-stressed society, groundwater use is expected to increase with time. To ameliorate problems related to high levels of nitrate, low-cost technologies will be required. One such technology based on adsorption using SMZ could be appropriate. Further studies will, however, be required to scale-up and optimise process variables.

\section{Acknowledgements}

The authors wish to extend their gratitude to Prof. Maggie Momba of the Department of Water Care, Tshwane University of Technology, for availing the UV spectrophotometer used for nitrate analysis.

\section{References}

ALTIN O, ÖZBELGE HÖ and DOGU T (1998) Use of general purpose adsorption isotherms for heavy metal-clay mineral interactions. J. Colloid Interface Sci. 198 (1) 130-140.

ATHANASIADIS K and HELMREICH B (2005) Influence of chemical conditioning on the ion exchange capacity and on kinetic of zinc uptake by clinoptilolite. Water Res. 39 (8) 1527-1532.

AYYASAMY PM, SHANTHI K, LAKSHMANAPERUMALSAMY P, LEE SJ, CHOI NC and KIM DJ (2007) Two-stage removal of nitrate from groundwater using biological and chemical treatments. J.Biosci. Bioeng. 104 (2) 129-134.

BAE BU, JUNG YH, HAN WW and SHIN HS (2002) Improved brine recycling during nitrate removal using ion exchange. Water Res. 36 (13) 3330-3340.

BOHDZIEWICZ J, BODZEK M and WASIK E (1999) The application of reverse osmosis and nanofiltration to the removal of nitrates from groundwater. Desalination 121 (2) 139-147.

BOUWER H (1989) Agricultural contaminants: Problems and solutions. Water Environ. Technol. 292-297.

BOWMAN RS, SULLIVAN EJ and LI Z (2000) Uptake of cations, anions and non polar organic molecules by surfactant modified clinoptilolite rich tuff. In: Collela CM and Mumpton FA (eds.) Natural Zeolites for the Third Millenium. A. De Frede Editore, Naples, Italy.

CENGELOGLU Y, TOR A, ERSOZ M and ARSLAN G (2006) Removal of nitrate from aqueous solution by using red mud. Sep. Purif. Technol. 51 374-378.

CHABANI M, AMRANE A and BENSMAILI A (2006) Kinetic modelling of the adsorption of nitrates by ion exchange resin. Chem. Eng. 125(2) 111-117.

CHATTERJEE S and WOO SH (2009) The removal of nitrate from aqueous solutions by chitosan hydrogel beads. J. Hazardous Mater. 164 1012-1018

CHATTERJEE S, LEE MW, LEE DS and WOO SH (2009) Nitrate removal from aqueous solutions by cross-linked chitosan beads conditioned with sodium bisulfate. J. Hazardous Mater. 166 (1) 508-513.a.

CLIFFORD D and LIU X (1993) Ion exchange for nitrate removal. J. Am. Water Works Assoc. 85 (4) 135-143.

COLVIN C, TREDOUX G, CLARKE S, LE MAITRE D, ENGELBRECHT P and MAHERRY A (2008) Integration goes underground: A review of groundwater research in support of sustainable development in South Africa. Proc. 'Science Real and Relevant', 2nd CSIR Biennial Conference, 17-18 November 2008, CSIR International Convention Centre, Pretoria.

HO YS and MCKAY G (1999) Pseudo-second order model for sorption processes. Process Biochem. 34 (5) 451-465.

HUI KS, CHAO CYH and KOT SC (2005) Removal of mixed heavy metal ions in wastewater by zeolite $4 \mathrm{~A}$ and residual products from recycled coal fly ash. J. Hazardous Mater. 127 (1-3) 89-101. 
INGLEZAKIS VJ (2005) The concept of "capacity" in zeolite ionexchange systems. J. Colloid Interface Sci. 281 (1) 68-79.

KUMAR AB, SADHANA SR, KUMAR NL, JUWARKAR AA and DEVOTTA S (2006) Surfactant modified zeolite as a slow release fertilizer for phosphorus. J. Agric. Food Chem. 54 4773-477.

LI Z and BOWMAN RS (2001) Regeneration of surfactant-modified zeolite after saturation with chromate and perchloroethylene. Water Res. 35 (1) 322-326.

MAŽEIKIENĖ A, VALENTUKEVIČIENĖ M, RIMEIKA M, MATUZEVIČIUS AB and DAUKNYS R (2008) Removal of nitrates and ammonium ions from water using sorbent zeolite (clinoptilolite). J. Environ. Eng. Landscape Manage. 16 (1) 38-44.

MONTEIRO MIC, FERREIRA FN, OLIVEIRA NMM and AVILA AK (2003) Simplified version of the sodium salicylate method for nitrate analysis in drinking waters. Anal. Chim. Acta. 477 (1) 125-129.

ONYANGO MS (2006) Modelling the Diffusion and Reaction of Water Soluble Ions of Arsenic, Fluoride and Phosphate on Surface-Tailored Zeolite Adsorbents. Ph.D. Dissertation, Nagoya University, Japan. 199 pp.

ONYANGO MS and MATSUDA H (2006) Fluoride removal from water using adsorption technique. In: Tressaud A (ed.) Fluoride and Environment: Agrochemical, Archaeology, Green Chem. and Water (Advances in Fluorine Science, Volume 2). Elsevier B.V., The Netherlands. 1-48.

ONYANGO MS, KOJIMA Y, AOYI O, BERNADO EC and MATSUDA H (2004) Adsorption equilibrium modeling and solution chemistry dependence of fluoride removal from water by trivalentcation-exchanged zeolite. J. Colloid Interface Sci. 279 (2) 341-350.

ÖZTURK N and BEKTAS EI (2004) Nitrate removal from aqueous solution by adsorption onto various materials. J. Hazardous Mater 112 155-162.

PIETERSEN K (2005) Groundwater crucial to rural development. Proc. Bienn. Groundwater Conf. S. Afr., 7-9 March, 2005, CSIR International Convention Centre, Pretoria.
RANCK MJ, BOWMAN RS, WEEBER JL, KATZ LE and SULLIVAN EJ (2005) Btex removal from produced water using surfactant modified zeolite. J. Environ. Eng. 131 (3) 434-442.

SAAD R, BELKACEMI K and HAMOUDI S (2007) Adsorption of phosphate and nitrate anions on ammonium-functionalized MCM48: Effects of experimental conditions. J. Colloid Interface Sci. 311 (2) 375-381.

SAMATYA S, KABAY N, YÜKSEL Ü, ARDA M and YÜKSEL (2006) Removal of nitrate from aqueous solution by nitrate selective ion exchange resins. Reactive Functional Polym. 66 (11) 1206-1214.

SCHICK J, CAULLET P, PAILLAUD JL, PATARIN J and CALLAREC CM (2010) Batch-wise nitrate removal from water on a surfactant modified zeolite. Micropor. Mesopor. Mat. 132 (3) 395-400.

SCHOEMAN JJ and STEYN A (2003) Nitrate removal with reverse osmosis in a rural area in South Africa. Desalination 155(1) 15-26.

STADLER S, OSENBRÜCK K, KNÖLLER K, SUCKOW A, SÜLTENFUß J, OSTER H, HIMMELSBACH T and HÖTZL H (2008) Understanding the origin and fate of nitrate in groundwater of semi-arid environments. J. Arid Environ. 72 (10) 830-1842.

UYSAL M and AR I (2007) Removal of Cr(VI) from industrial wastewaters by adsorption Part I. Determination of optimum conditions. J. Hazardous Mater. 149 (2) 482-491.

WINGENFELDER U, FURRER G and SCHULIN R (2006) Sorption of antimonite by HDTMA-modified zeolite. Micropor. Mesopor. Mater. 95 (1-3) 265-271.

YUSOF AM and MALEK NA (2009) Removal of Cr (VI) and As (V) from aqueous solutions by HDTMA-modified zeolite Y. J. Hazardous Mater. 162 (2-3) 1019-1024.

ZHOU Q, HE HP, ZHU JX, SHEN W, FROST RL and YUAN P (2008) Mechanism of $p$-nitrophenol adsorption from aqueous solution by HDTMA $^{+}$-pillared montmorillonite - Implications for water purification. J. Hazardous Mater. 154 (1-3) 1025-1032. 